\title{
TO STUDY THE ASSOCIATION OF PRISM SCORE WITH MORTALITY AND PREDICTION OF PROBABILITY OF DEATH ACCORDING TO PRISM-III SCORE
}

\author{
Anil Bhoi ${ }^{1}$, Vandana Bhoi ${ }^{2}$
}

${ }_{1}^{1}$ Associate Professor, Department of Paediatrics, PIMSR, Islampur, Maharashtra.

${ }^{2}$ Associate Professor, Department of Community Medicine, PIMSR, Islampur, Maharashtra.

\section{ABSTRACT}

\section{BACKGROUND}

Scoring system such as the Paediatric Risk of Mortality (PRISM-III) Score is widely used in paediatric intensive care worldwide; the III generation scoring system that allows assessment of severity of illness and mortality risk adjustment. Paediatric Risk of Mortality (PRISM-III) Score is considered to be the most effective in predicting the risk of mortality. PRISM-III Score is used as predictor of mortality and also to evaluate our health care service in comparison to worldwide standards. It would also provide a background for further progression in health care quality control in the hospitals.

\section{MATERIALS AND METHODS}

The present prospective observational study was carried out during October 2015 to September 2016 in Paediatric Intensive Care Unit (PICU) of Prakash Institute of Medical Sciences and Research, Urun-Islampur. All patients admitted to PICU during October 2015 to September 2016 who fulfilled the inclusion criteria were enrolled in the study.

\section{RESULTS}

Out of 101 patients from PICU, average PRISM-III score of patients was $9.80 \pm 6.51$. We had 58 children with PRISM-III score < 10, out of which only one (1.7\%) died, whereas 7 (77.8\%) out of 9 died when the score was more than 20 . We found that mortality was $1.7 \%$ for PRISM-III scores $<10$ increasing to $77.8 \%$ for $>20$ score. This showed that there was a geometrical increase in the mortality with increase in the PRISM-III score values, which was found to be statistically significant. We observed that except PRISM-III score, the remaining variables like age, sex and cause of illness showed no significant association with the mortality ( $p$ > 0.11). The results of goodness of the prediction model as seen by Hosmer-Lemeshow goodness of fit chi-square showed that the model of PRISM-III designed in this study has been well fit for prediction of mortality rate in our PICU with p-value of 0.617 for total studied patients.

\section{CONCLUSION}

PRISM-III Score has good predictive value in assessing the probability of mortality.

\section{KEY WORDS}

PICU, Prism Score, Paediatric Intensive Care, Mortality.

HOW TO CITE THIS ARTICLE: Bhoi A, Bhoi V. To study the association of PRISM score with mortality and prediction of probability of death according to PRISM-III score. J. Evolution Med. Dent. Sci. 2018;7(19):2347-2350, DOI: 10.14260/jemds/2018/529

\section{BACKGROUND}

The clinical judgement of the severity of a disease process is not uniform. Prediction of patient outcome is important for the patients and family and is relevant for policy formulation and resource allocation. ${ }^{1}$ In developing countries, most of the units lack technical equipment. The staff available in PICU settings is usually inadequately trained and clinical experience regarding Paediatric intensive care is limited. Hence, when patients with varying prognosis and degrees of clinical severity are being treated, the final strategy of employing the resources available optimally at such units is often uncertain. ${ }^{2}$ Hence, to optimise the use of resources and proper treatment of sick patients in PICUs, intensive care scoring systems are devised to determine probable outcome of the patients being admitted into ICU. ${ }^{3}$

'Financial or Other Competing Interest': None.

Submission 21-03-2018, Peer Review 17-04-2018,

Acceptance 24-04-2018, Published 07-05-2018.

Corresponding Author:

Vandana Bhoi,

Ganeshnagar, Near ST Stand,

Islampur-415409,

Tal-Walwa, Dist-Sangli, Maharashtra

E-mail:drvabhoi@gmail.com

DOI: $10.14260 /$ jemds $/ 2018 / 529$

\section{(c) $($ ) $९$}

PICU scoring systems are mostly studied for developed nation's settings. Data from developing nations has conflicting results. 4,5 There are different scoring systemsPaediatric Logistic Organ Dysfunction (PELOD), Paediatric Index of Mortality (PIM) 1 and 2, and PRISM I, II, III- used in management of paediatric patients in PICUs worldwide. ${ }^{6}$ In their study compared the performance of the PRISM, PELOD and the PIM-2 at a general PICU, investigating the relationship between observed outcome (death/ survival) and the mortality and survival rates estimated by the three scores. ${ }^{6}$ Both PRISM and PIM2 had good discrimination and calibration in PICU in developing countries circumstances. PELOD had poor performance and is not validated in PICU setting.

PRISM (Paediatric Risk of Mortality) score is the principle score used in paediatric population. Paediatric risk of mortality (PRISM) score is considered to be the most effective in predicting the risk of mortality in PICU.1,7,8 Data on validity of PRISM outside USA and Europe is limited, especially in developing countries. ${ }^{1,5,7,9,10}$

The practice of paediatric critical care is dynamic and evolving process. Paediatric population is a vulnerable group necessitating standard care for medically and surgically ill children. Standard care is not well defined for Paediatric 
critical care, as most of the protocols and practices in Paediatric intensive unit (PICU) are actually extrapolation of adult critical care. ${ }^{11}$

The ideal probability model scoring system would be institution independent and population independent scoring. ${ }^{12}$

The objective of present study was to determine the performance of the PRISM in our PICU to compare the predicted mortality with the observed mortality and determine the suitability of each for monitoring the quality of intensive care in our unit.

\section{Aims and Objectives}

To study the association of PRISM-III score with mortality and prediction of probability of death according to PRISM-III score.

\section{MATERIALS AND METHODS}

The present observational study was carried out during October 2015 to September 2016 in Paediatric Intensive Care Unit (PICU) of Prakash Institute of Medical Sciences and Research, Urun-Islampur. All patients admitted to PICU during October 2015 to September 2016 who fulfilled the inclusion criteria were enrolled in the study.

\section{Study Design}

Prospective observational study.

\section{Settings}

Prakash Institute of Medical Sciences and Research, UrunIslampur, Maharashtra. Prakash Institute of Medical Sciences and Research is a Medical College, as tertiary care unit giving services as referral unit for sick paediatrics patients. Five (5) bedded Paediatric Intensive Care Unit (PICU) is with the Department of Paediatrics. All the patients are attended by paediatric resident. 24 hours service is available of Microbiology and Pathology department of hospital for laboratory investigation.

\section{Duration of Study}

October 2015 to September 2016- One year.

\section{Inclusion Criteria}

All Sick Children Aged 1 Month to 12 Years admitted in PICU fulfilling the following Criteria-

1. With evidence of respiratory failure.

2. With cardiovascular shock.

3. With acute neurological deterioration.

4. With acute renal failure requiring dialysis.

5. With bleeding disorders requiring massive transfusion.

\section{Exclusion Criteria}

1. Death within the first $10 \mathrm{hrs}$. of PICU admission.

2. Post-operative patients.

\section{Consent}

Informed consent was taken from the family and the admitting paediatric consultant.
Sample Size- 100 sick paediatric patients admitted in PICU.

\begin{tabular}{|c|c|c|c|c|}
\hline Variable & \multicolumn{3}{|c|}{ Age and Ranges } & Score \\
\hline \multirow{2}{*}{ Temperature } & \multicolumn{3}{|c|}{$<91.4$ and $>104^{\circ} \mathrm{F}$} & 3 \\
\hline & \multicolumn{3}{|c|}{$91.5-103.9^{\circ} \mathrm{F}$} & 0 \\
\hline \multirow{4}{*}{$\begin{array}{l}\text { Systolic blood } \\
\text { pressure } \\
(\mathrm{mmHg})\end{array}$} & Infant & Child & Adolescent & \\
\hline & $45-65$ & $55-75$ & $65-85$ & 3 \\
\hline & $<45$ & $<55$ & $<65$ & 7 \\
\hline & $>65$ & $>75$ & $>85$ & 0 \\
\hline \multirow{3}{*}{$\begin{array}{l}\text { Heart rate } \\
\text { (beats/min) }\end{array}$} & $215-222$ & $185-205$ & $145-155$ & 3 \\
\hline & $>225$ & $>205$ & $>155$ & 4 \\
\hline & $<215$ & $<185$ & $<145$ & 0 \\
\hline \multirow{4}{*}{ Pupils } & \multicolumn{3}{|c|}{ All ages } & \\
\hline & \multicolumn{3}{|c|}{ One fixed and one reactive } & 7 \\
\hline & \multicolumn{3}{|c|}{ Both non-reactive } & 11 \\
\hline & \multicolumn{3}{|c|}{ Both normal in size and reaction } & 0 \\
\hline \multirow{3}{*}{$\begin{array}{c}\text { Level of } \\
\text { consciousness }\end{array}$} & \multicolumn{3}{|c|}{ All ages } & \\
\hline & \multicolumn{3}{|c|}{ Stupor/coma $\left(\mathrm{GCS}^{*}<8\right)$} & 5 \\
\hline & \multicolumn{3}{|c|}{$>8$} & 0 \\
\hline \multirow[t]{5}{*}{$\mathrm{PH}$} & \multicolumn{3}{|c|}{ All ages } & \\
\hline & & $7-7.28$ & & 2 \\
\hline & & $<7$ & & 6 \\
\hline & & $>7.55$ & & 3 \\
\hline & & $7.28-7.48$ & & 0 \\
\hline & & All ages & & \\
\hline Total $\mathrm{CO}_{2}$ & & $5-16.9$ & & 2 \\
\hline$(\mathrm{mmol} / \mathrm{L})$ & & $<5$ & & 6 \\
\hline & & $>34$ & & 4 \\
\hline & & $17-33.9$ & & 0 \\
\hline & & All ages & & \\
\hline $\mathrm{Pa}=(\mathrm{mmHa})$ & & $42-49.9$ & & 3 \\
\hline Pav2 (mmng) & & $<42$ & & 6 \\
\hline & & $>50$ & & 0 \\
\hline & & All ages & & \\
\hline & & $50-75$ & & 1 \\
\hline PCU2 (mmHg) & & $>75$ & & 3 \\
\hline & & $<50$ & & 0 \\
\hline & & All ages & & \\
\hline Glucose $(\mathrm{mg} / \mathrm{dL})$ & & $>200$ & & 2 \\
\hline & & $<200$ & & 0 \\
\hline & & All ages & & \\
\hline (mmol/I) & & $>6.9$ & & 3 \\
\hline & & $<6.9$ & & 0 \\
\hline & Infant & Child & Adolescent & \\
\hline creatinine & $>0.90$ & $>0.90$ & $>1.30$ & 2 \\
\hline & $<0.90$ & $<0.90$ & $<1.30$ & 0 \\
\hline Blood Urea & & All ages & & \\
\hline Nitrogen & & $>14.9$ & & 3 \\
\hline$(\mathrm{BUN})(\mathrm{mg} / \mathrm{dL})$ & & $<14.9$ & & 0 \\
\hline & & All ages & & \\
\hline$\left(\mathrm{cell} / \mathrm{mm}^{3}\right)$ & & $<3000$ & & 4 \\
\hline & & $>3000$ & & 0 \\
\hline & & All ages & & \\
\hline & & $0,000-2,0$ & 0,00 & 2 \\
\hline Platelet count & &, $000-99$ & & 4 \\
\hline & & $<50,000$ & & 5 \\
\hline & & $>2,00,00$ & & 0 \\
\hline Prothrombin & & All ages & & \\
\hline time (PT) (sec) & & 22 or PT1 & $>57$ & 3 \\
\hline $\begin{array}{c}\text { OR } \\
\text { Partial } \\
\text { thromboplastin } \\
\text { time (PTT) (sec) }\end{array}$ & & 22 or PT1 & $<57$ & 0 \\
\hline & Table 1. & ISM Score & & \\
\hline
\end{tabular}

*GCS- Glasgow Coma Scale 
Data was categorised in 3 Groups depending on the Age1 month to 1 year, 1 to 6 years, 6 to 12 years.

\section{Groups on the Basis of the Total PRISM-III Score}

The total PRISM-III score for each patient was calculated by summing up the individual score of each parameter and patients were grouped into 3 groups as below:

- Group I- 0 to 9

- Group II- 10 to 19

- Group III- 20+

\section{In each group following parameters were noted}

- Number of patients alive.

- Number of patients dead.

Number of total deaths in each category was recorded and it was compared against the expected number of deaths in each category.

The effectiveness of PRISM-III score was assessed by comparing observed deaths versus expected deaths.

\section{Data Analysis}

Percentage (\%), the association between the study variables namely age, sex, PRISM-III score and diagnosed cause of illness with the ICU mortality was tested using contingency/trend Chi-square test as appropriate. The appropriateness or the aptness of model is assessed by Hosmer-Lemeshow goodness of fit Chi-square test. The statistical analysis was done in 11 version of SPSS software.

\section{RESULTS}

\begin{tabular}{|c|c|}
\hline $\begin{array}{c}\text { Total no. of patients admitted at PICU of PIMSR in } \\
\text { the study period }\end{array}$ & 300 \\
\hline Number of patients eligible for study & 150 \\
\hline Number of babies excluded & 49 \\
\hline Post-operative patients & 44 \\
\hline Death within the first 10 hours of PICU admission & 5 \\
\hline Number of patients enrolled & 101 \\
\hline
\end{tabular}

\begin{tabular}{|c|c|}
\hline Variable & Number (\%) $n=101$ \\
\hline \multicolumn{2}{|c|}{ Age } \\
\hline 1 month - 1 year & $26(25.7)$ \\
\hline $1-6$ years & $49(48.5)$ \\
\hline $6-12$ years & $26(25.7)$ \\
\hline Mean Age (years) & $3.5 \pm 3.8$ \\
\hline \multicolumn{2}{|c|}{ Sex } \\
\hline Male & $52(51.5)$ \\
\hline Female & $49(48.5)$ \\
\hline \multicolumn{2}{|c|}{ Causes of Illness } \\
\hline Respiratory & $24(23.76)$ \\
\hline CNS & $26(25.74)$ \\
\hline Sepsis & $14(13.86)$ \\
\hline Others & $37(36.63)$ \\
\hline \multicolumn{2}{|c|}{ PRISM Score } \\
\hline$<10$ & $58(57.42)$ \\
\hline $10-19$ & $34(33.67)$ \\
\hline $20+$ & $9(8.91)$ \\
\hline Mean PRISM Score & $9.80 \pm 6.51$ \\
\hline
\end{tabular}

\begin{tabular}{|c|c|c|c|c|}
\hline Variable & $\begin{array}{c}\text { Number (\%) } \\
n=101\end{array}$ & $\begin{array}{c}\text { Died (\%) } \\
n=17 \\
\end{array}$ & $\begin{array}{c}\text { Alive (\%) } \\
\mathrm{n}=84\end{array}$ & P value \\
\hline \multicolumn{4}{|c|}{ Age } & \multirow{4}{*}{0.53} \\
\hline 1 month-1 year & $26(25.7)$ & $3(11.5)$ & $23(88.5)$ & \\
\hline $1-6$ years & $49(48.5)$ & $8(16.3)$ & $41(83.7)$ & \\
\hline $6-12$ years & $26(25.7)$ & $6(23.1)$ & $20(76.9)$ & \\
\hline \multicolumn{4}{|c|}{ Sex } & \multirow{3}{*}{0.69} \\
\hline Male & $52(51.5)$ & $8(15.4)$ & $44(84.6)$ & \\
\hline Female & $49(48.5)$ & $9(18.4)$ & $40(81.6)$ & \\
\hline \multicolumn{4}{|c|}{ Causes of Illness } & \multirow{5}{*}{0.175} \\
\hline Respiratory & $24(23.76)$ & $5(20.8)$ & $19(79.2)$ & \\
\hline CNS & $26(25.74)$ & $1(3.8)$ & $25(96.2)$ & \\
\hline Sepsis & $14(13.86)$ & $2(14.3)$ & $12(85.7)$ & \\
\hline Other & $37(36.63)$ & $9(24.3)$ & $28(75.7)$ & \\
\hline
\end{tabular}

\begin{tabular}{|c|c|c|c|}
\hline $\begin{array}{c}\text { PRISM } \\
\text { Score }\end{array}$ & $\begin{array}{c}\text { Death } \\
\mathbf{n = 1 7}\end{array}$ & $\begin{array}{c}\text { Survived } \\
\mathbf{n = 8 4}\end{array}$ & \multirow{2}{*}{ P value } \\
\cline { 1 - 3 }$<10$ & $1(1.7 \%)$ & $57(98.3 \%)$ & \multirow{2}{*}{0.000} \\
\cline { 1 - 3 } $10-19$ & $9(26.5 \%)$ & $25(73.5 \%)$ & \\
\hline $20+$ & $7(77.8 \%)$ & $2(22.2 \%)$ & \\
\cline { 1 - 3 } Table 4. Association of PRISM-III Score and Mortality \\
\hline
\end{tabular}

\begin{tabular}{|c|c|}
\hline PRISM-III Score & Probability of Death (\%) \\
\hline 5 & 1.6 \\
\hline 10 & 7.9 \\
\hline 15 & 31.7 \\
\hline 20 & 71.4 \\
\hline 25 & 93.1 \\
\hline 30 & 98.6 \\
\hline \multicolumn{2}{|c|}{ Table 5. Prediction of Probability of Death according to } \\
PRISM-III Score \\
\hline
\end{tabular}

\begin{tabular}{|c|c|c|c|c|}
\hline $\begin{array}{c}\text { PRISM-III } \\
\text { Score }\end{array}$ & \multicolumn{2}{|c|}{ Survived } & \multicolumn{2}{c|}{ Death } \\
\hline & Observed & Expected & Observed & Expected \\
\hline$<10$ & $57(67.9)$ & $\begin{array}{c}56.99 \\
(67.9)\end{array}$ & $1(5.9)$ & $1.002(5.9)$ \\
\hline $10-19$ & $25(29.8)$ & $25(29.8)$ & $9(52.9)$ & $9(52.9)$ \\
\hline $20+$ & $2(2.4)$ & $2(2.4)$ & $7(41.2)$ & $7(41.2)$ \\
\hline \multicolumn{3}{|c|}{ Table 6. Goodness of the Predictive Model } \\
\hline
\end{tabular}

Hosmer and Lemeshow Chi-square 0.25, $p=0.617$

\section{DISCUSSION}

The overall performance of PRISM Score was good with reasonable agreement between observed and expected mortality across the most mortality risk intervals. In study, PRISM Score was associated with an increase in mortality. The prediction of probabilities of death using PRISM Score in our study showed the probability of death increases significantly with increase in PRISM Score. There was no significant difference between the observed and predicted outcomes suggesting PRISM score. This was comparable to other studies like D. Singhal et al, ${ }^{1}$ EL-Nawawy A ${ }^{7}$ and Roopa Bellad et al. ${ }^{13}$ We studied 101 children from Paediatric Intensive Care Unit admission to final short-term outcome based on PRISM Scoring System. We had out of 101 children 52 boys and 49 girls in the age range of 1 month to 12 years. The average PRISM-III Score of subjects was $9.80 \pm 6.51$ (range 0 to 32 ).

Respiratory conditions (23.76\%), CNS conditions (25.74\%), septicaemia (13.86\%) followed by other conditions (36.63\%) were the causes of illness diagnosed on admission. The others include cardiovascular disorders $(n=5)$, infection 
$(n=9)$, gastrointestinal and liver disorders, hepatitis, fulminant hepatic failure $(n=4)$, gastroenteritis with severe dehydration $(n=2)$, poisoning $(n=1)$, renal diseases $(n=4)$, wasp bite $(n=2)$, endocrine $(n=3)$, kerosene poisoning $(n=1)$, severe anaemia $(n=3)$, metabolic disorders $(n=3)$. The similar findings were observed by D. Singhal et al. 1

We had 58 patients in Group 1 (PRISM-III < 10), 34 patients in Group 2 (PRISM-III 10 - 20) and 9 patients in Group 3 (PRISM-III 20+). Similar findings were observed by D. Singhal et al, ${ }^{1}$ Balkrishnan $G$ et al, ${ }^{10}$ Poonam Bhadoria et al,12 Roopa Bellad et al, ${ }^{13}$ Pollack MM et al, ${ }^{14}$ Roshani N Taori et $\mathrm{al}^{15}$ in their studies.

We had 58 children with PRISM-III Score $<10$, out of which only one $(1.7 \%)$ died, whereas $7(77.8 \%)$ out of 9 died when the score was more than 20 . We found that mortality was $1.7 \%$ for PRISM-III scores < 10 increasing to $77.8 \%$ for $>20$ score. This showed that there was a geometrical increase in the mortality with increase in the PRISM-III score values, which was found to be statistically significant. We observed that except PRISM-III Score the remaining variables like age, sex and cause of illness showed no significant association with the mortality $(p>0.11)$.

The predicted probability of PICU mortality from our data showed that a PRISM-III score of above 15 yielded 32\% probability of death in PICU. The predicted probability of PICU mortality showed that a child with PRISM score of 5 had $1.6 \%$ chance of dying in PICU and a child with a score of 30 had $98.6 \%$ probability of dying in the PICU.

The results of goodness of the prediction model as seen by Hosmer-Lemeshow goodness of fit Chi-square showed that the model of PRISM-III designed in this study has been well fit for prediction of mortality rate in our PICU with $p$ value of 0.617 for total studied patients.

\section{CONCLUSION}

According to the results of our study, health care quality in the PICU of PIMSR Hospital is at par with similar worldwide health care systems. PRISM-III score can be reliably used in our PICU as predictor of mortality. The prediction of ICU mortality based on PRISM-III score is valid and moderately reliable. PRISM-III score has good predictive value in assessing the probability of mortality in relation to children admitted to PICU under Indian circumstances.

\section{REFERENCES}

[1] Singhal D, Kumar N, Puliyel JM, et al. Prediction of mortality by application of prism score in intensive care unit. Indian Pediatrics 2001;38(7):714-9.

[2] Pollack MM, Cuerdon TT, Patel KM, et al. Impact of quality-of-care factors on pediatric intensive care unit mortality. JAMA 1994;272(12):941-6.

[3] Seneff M, Knaus WA. Predicting patient outcome from intensive care: a guide to APACHE, MPM, SAPS, PRISM and other prognostic scoring systems. J Intensive Care Med 1990;5(1):33-52.
[4] Maratha VF, Garcia PC, Piva JP, et al. Comparison of two prognostic scores (PRISM and PIM) at a pediatric intensive care unit. J Pediatr (Rio J) 2005;81(3):25964.

[5] Wells M, Riera-Fanego JF, Luyt DK, et al. Poor discriminatory performance of the Paediatric Risk of Mortality (PRISM) score in a South African intensive care unit. Crit Care Med 1996;24(9):1507-13.

[6] Qureshi AU, Ali AS, Ahmad TM. Comparisons of three prognostic scores (PRISM, PELOD AND PIM2) at paediatric intensive care unit under Pakistani circumstances. J Ayub Med Coll Abbottabad 2007;19(2):49-53.

[7] El-Nawawy A. Evaluation of the outcome of patients admitted to the paediatric intensive care unit in Alexandria using the paediatric risk of mortality (PRISM) score. J Trop Paediatr 2003;49(2):109-14.

[8] Castello FV, Cassano A, Gregory P, et al. The Paediatric Risk of Mortality (PRISM) score and Injury Severity Score (ISS) for predicting resource utilization and outcome of intensive care in paediatric trauma. Crit Care Med 1999;27(5):985-8.

[9] Thukral A, Lodha R, Irshad M, et al. Performance of Paediatric Risk of Mortality (PRISM), Paediatric Index of Mortality (PIM), and PIM2 in a paediatric intensive care unit in a developing country. Paediatr Crit Care Med 2006;7(4):356-61.

[10] Balkrishnan G, Aitchison T, Hallworth D, et al. Prospective evolution of the Paediatric Risk of Mortality (PRISM) score. Arch Dis Child 1992;67:196200.

[11] Gemke RJ, Bonsel GJ, Van Vught AJ. Effectiveness and efficiency of a Dutch paediatric intensive care unit: validity and application of the paediatric risk of mortality score. Critical Care Med 1994;22(9):147784.

[12] Bhadoria P, Bhagwat AG. Severity scoring systems in Paediatric Intensive Care Units. Indian Journal of Anesthesia 2008;52(Suppl (5)):663-75.

[13] Bellad R, Rao S, Patil VD, et al. Outcome of intensive care unit patients using paediatric risk of mortality (PRISM) Score. Indian Paediatrics 2009;46(12):10912.

[14] Pollack MM, Patel KM, Ruttimann UE. PRISM III: an updated paediatric risk of mortality score. Crit Care Med 1996;24(5):743-52.

[15] Taori RN, Lahiri KR, Tullu MS. Performance of PRISM (Paediatric Risk of Mortality) score and PIM (Paediatric Index of Mortality) score in a tertiary care paediatric ICU. Indian J Paediatr 2010;77(3):267-71. 